\title{
SALA DE AULA: ESPAÇO DA ARTE E DO AFETO
}

\section{Gisele Filippini Gomes}

\section{RESUMO}

O presente texto discute a questão da arte como motivadora na relação de afetividade entre professor e aluno, influenciando a própria dinâmica do espaço da sala de aula. A partir da experiência relatada, será possível perceber a importância do desenvolvimento de projetos relacionado à artes, enquanto um elemento facilitador do processo de aprendizagem, mobilizando o aluno para uma formação mais humana e sensível.

\section{PALAVRAS-CHAVES}

Relação professor-aluno; Afetividade, Arte.

\section{CLASSROOM: PLACE OF THE ART AND THE AFFECTION}

\section{ABSTRACT}

The present text argues the question of the art as motivated in the affectivity between teacher and student, influencing the proper dynamics of the classroom. From the told experience, it will be possible to perceive the importance of the development of projects related to the arts, while a important element of the learning process, mobilizing the student for a formation more sensible.

\section{KEYWORDS}

Relation teacher-student; Afectivity; Art's class

\section{INTRODUÇÃO}

A arte não existe para reproduzir o visível, mas para tornar visível aquilo que está mais além dos olhos.

Paul Klee

Quando no início do ano letivo de 2004, optei em escolher minhas aulas como professora substituta da rede municipal de Campinas, tive a gratificante oportunidade de retornar à Escola Padre Francisco Silva, digo retornar pois já havia trabalhado nesta unidade escolar, no início da minha carreira docente, em 2001. 


\section{DIMENSÕES RELACIONAIS NA ESCOLA Grupo de Pesquisa em Ensino Superior}

Minha opção por trabalhar novamente neste espaço escolar baseou-se muito nas relações de afeto e companheirismo que vivenciei, e na vontade de compartilhar meus sonhos e idéias com estas pessoas que tão bem me acolheram. Quando cheguei à escola, algumas coisas haviam mudado, os professores seguiam empenhados em buscar soluções para alguns dilemas relacionados à unidade escolar e à própria prática pedagógica, como: a indisciplina e a busca de um trabalho mais interdisciplinar dentro da escola. Conjuntamente a este empenho de buscar soluções, estes professores faziam parte de um projeto chamado: “Escola singular, ações plurais” apoiados pela universidade em parceria com profissionais da UNICAMP, em especial os professores Ana Aragão e Guilherme Prado . Agora fazendo parte deste grupo, pudemos encontrar um espaço semanal para estudar e conversar sobre nossas práticas.

Esses encontros aconteciam em dois grupos (Quinta a oitava série e primeira a quarta séries) todas as segundas feiras, com duas horas de duração cada um. Buscávamos discutir na teoria, textos e autores que viessem incorporar nossa prática e solucionar alguns de nossos dilemas. Discutimos, entre outros temas, a motivação em sala de aula, a aprendizagem, a avaliação e a adolescência. Este trabalho era chamado de grupo de estudo semanal (GT), no final de cada conversa fazíamos, por ordem alfabética, relatos escritos de nossa experiência e do que havia sido discutido naquele dia. Era muito difícil, mas era um importante exercício para aprendermos a expressar pensamentos e nos colocar realmente como participantes do processo de estudo coletivo. Posso afirmar que este trabalho unificado com professores, funcionários e a universidade foi fundamental na construção desta escola tão singular e com profissionais tão dispostos em construir algo coletivo, e com tantas ações plurais.

Além deste GT semanal, formamos, a partir de outubro, subgrupos de estudo, estes originaramse a partir do apoio de pesquisa oferecido pela FAPESP, os professores apoiados puderam intensificar seus estudos dedicando-se a um objeto específico de pesquisa.

O nosso grupo surgiu pela afinidade ao tema: Relações interpessoais na escola, composto por mim, professora de Atividade Curricular Especial, pela Maristela Marçal, professora de Educação Física e Adriana Pierini, Orientadora Pedagógica desta unidade escolar.

Foi desta maneira que conjuntamente ao GT semanal passamos a conversar sobre as relações interpessoais na escola, chamando carinhosamente nosso subgrupo de Grupo do Afeto.

Apoiadas pela FAPESP durante três meses de trabalho e estudo dirigido dentro do projeto “Escola singular, ações plurais” na EMEF "Padre Francisco Silva”, discutimos as relações 


\section{DIMENSÕES RELACIONAIS NA ESCOLA Grupo de Pesquisa em Ensino Superior}

interpessoais na escola, mais especificamente, a relação professor-aluno. Acreditamos que as relações entre pessoas são fundamentais no processo de construção do conhecimento e da aprendizagem. Partindo deste pressuposto, vinculamos nossas discussões à importância da coletividade, da instituição escola, dos projetos que nela existem, e da relação afeto-cognição.

No primeiro momento de discussão de nosso grupo, conversamos sobre as diversas relações existentes na escola: projetos, aulas, espaços de vivências, tempo escolar, relações de afeto, planejamento, gestão escolar entre outros, e pudemos perceber que mais que um espaço de transmissão do conhecimento, a escola é também o espaço de relações afetivas e que estas relações são fundamentais na constituição do ser humano.

Permeado por este objetivo comum, passamos a buscar na bibliografia elementos teóricos que nos auxiliassem na discussão da importância da afetividade na relação professor-aluno-escolaaprendizagem.

Após o contato e leitura dos textos de Tassoni e Leite (2002), Almeida (1999) e Araújo (2002), entramos em contato com teorias que dão ênfase às interações sociais, a partir de pressupostos básicos de Wallon e Vygotsky. Socializando aquilo que lemos, destacamos algumas considerações importantes como: a afetividade é fundamental no processo ensino aprendizagem, sentimento e pensamento se fundem, diferença entre emoção e afetividade, afetividade e o resgate da auto estima a partir do exercício com o outro. Cada uma de nós destacou o que mais nos chamava a atenção a partir dos textos analisados, e ao conversar sobre a importância da relação de afeto em sala de aula, dos trabalhos em grupos, promovendo a relação entre os alunos, da importância de se motivar o trabalho pedagógico, pudemos perceber que esta discussão teórica embasava muito nossa prática em sala de aula, à medida que nos dava a sensação de que não estávamos sozinhas falando de nossa prática, existindo teóricos, que de uma certa forma, acreditavam naquilo que fazíamos. Esta contribuição foi fundamental para que pudéssemos acreditar em nossa pesquisa e em nossa prática de trabalho coletivo na escola.

Baseadas na leitura de Leite e Tassoni (2002) e Almeida (1999), identificamos, conversando sobre a nossa prática, que a afetividade é fundamental no processo ensino aprendizagem, desta forma, é extremamente importante percebermos que as relações afetivas estabelecidas entre a troca de pessoas são essenciais para o desenvolvimento do ser humano mais integrado. Como é possível verificar no trecho a seguir

(c) ETD - Educação Temática Digital, Campinas SP, v.7 , n. esp., p.33-45, jun. 2006 - ISSN: 1676-2592 


\section{DIMENSÕES RELACIONAIS NA ESCOLA Grupo de Pesquisa em Ensino Superior}

As relações afetivas se evidenciam, pois a transmissão do conhecimento implica, necessariamente, uma integração entre pessoas. Portanto, na relação professor-aluno, uma relação de pessoa para pessoa, o afeto está presente. (ALMEIDA, 1999, p. 107)

Outra contribuição da teoria nos permitiu discutir e descobrir que existe uma integração entre a afetividade e a inteligência, analisamos que as dimensões afetivas e cognitivas dos seres humanos deviam ser pensadas de forma conjunta, sem dualidade, como ocorria na visão tradicional.

A afetividade torna-se fundamental no processo de aprendizagem e do desenvolvimento cognitivo, e a sala de aula, desta forma, torna-se o espaço do afeto e da construção do saber.

Dantas (1992) contribuiu para nossa discussão pois nos proporcionou analisar que o afeto e o pensamento se fundem o tempo todo, se desenvolvem, se diferenciando e se completando. Começamos, a partir desta discussão com a teoria, observar em nossa pratica, que era impossível separar a relação de afeto estabelecida entre professor e aluno da produção de conhecimento, isto porque nossas atividades em sala de aula privilegiavam as interações entre os alunos, compostas de afeto e conhecimento. Esta discussão, de que pensamento e sentimento se fundem, pode ser verificada no trecho a seguir:

Os passos da inteligência são rigorosamente seguidos pela afetividade; cada nova aquisição é compartilhada conjuntamente, o que significa que a afetividade depende, para evoluir, de conquistas realizadas no plano da inteligência e vice-versa. (DANTAS, 1992, p. 101).

Outra importante contribuição teórica em nossas discussões está relacionada à questão da emoção e da afetividade. Sendo nosso foco de estudo as relações interpessoais, é de extrema importância diferenciarmos aquilo que é emoção daquilo que é afetividade, pois como neste processo de construção das relações existe o afeto, é necessário definirmos sua conceitualização.

Wallon (1968) estabelece uma distinção entre emoção e afetividade, afirmando que as emoções estão relacionadas aos nossos estados orgânicos, já a afetividade é algo mais amplo pois agrupa os sentimentos, que são de origem psicológica e as emoções, que são de origem biológica.

A partir destas constatações, começamos a discutir o quão importante são as relações de afeto estabelecidas entre professor e aluno e como é importante estarmos atentos às manifestações corporais de nossos alunos para entendermos o que querem nos falar. Tal constatação pode ser verificada nas palavras de Wallon (1968, p.116) quando afirma que “a emoção é o primeiro e mais forte vínculo entre os indivíduos. É fundamental observar o gesto, a mímica, o olhar, a expressão facial, pois estes são constitutivos da atividade emocional”. 


\title{
DIMENSÕES RELACIONAIS NA ESCOLA Grupo de Pesquisa em Ensino Superior
}

Discutimos também que a afetividade resgata no ser humano sua auto estima, a partir do exercício com o outro. Desta maneira, nossas mensagens corporais estão vinculadas à nossa autoimagem, e devem ser vistas como constitutivas do espaço de sala de aula e como parte formadora da autonomia. Isto pode ser percebido nos trabalhos em grupos realizados em aula, pois a partir da troca de experiência, do conflito de idéias são estabelecidos vínculos de afetividade, e o aluno ao se espelhar no outro, ou não, ao proporcionar troca de elementos culturais, resgata sua auto imagem e se constrói.

Este resgate da auto estima e a construção da auto imagem, são essencialmente importantes na construção da autonomia. Podemos verificar esta discussão no trecho que segue:

\begin{abstract}
Cada ser humano constrói para si uma imagem que julga representa-lo, com a qual se identifica e se confunde. Essa imagem, portanto, desliza do parecer para o ser, quando então, imagem e sujeito constituem um mesmo e único valor. Não se trata, porém, de algo apenas racionalizado cognitivamente no nível da consciência, pois essa auto-imagem possui uma dimensão afetiva em sua constituição, que também se relaciona com os valores de cultura e com a constituição biofisiológica do corpo que o sedia. (HARKOT, 1999, p. 68)
\end{abstract}

A partir destas discussões, nos dedicamos a definir individualmente o objeto de estudo a ser trabalhado. A visita da Ana Aragão em nosso subgrupo foi fundamental neste processo, isto porque ainda estávamos um pouco perdidas no tema ao qual iríamos nos dedicar, e foi conversando sobre nossas discussões e relacionando-as com o que fazíamos em sala de aula, que definimos um pequeno caminho a ser percorrido. A partir desta conversa dediquei-me a definir individualmente o objeto de estudo a ser trabalhado e as teorias que pudessem me auxiliar. Passei, então, a analisar a importância da afetividade na formação do ser humano a partir da minha prática docente, o projeto de dança realizado com todos os alunos desta unidade escolar, chamado Movimentarte, e as aulas de Filosofia Ética e Cidadania ${ }^{2}$.

Meu objetivo inicial como docente consistiu em analisar que as relações afetivas ganhavam maior intensidade quando vinculadas a um trabalho que envolvesse a expressão do indivíduo através de instrumentos artísticos diferenciados, desta forma, a vivência com a dança e a utilização de estratégias de aula vinculadas à expressão pela arte pareciam intensificar as relações de afeto entre professoraluno sem desvincular o objeto de conhecimento.

O texto de Moraes (1994) me auxiliou muito na busca de algumas definições sobre os caminhos do meu objeto de pesquisa, por meio da leitura deste livro comecei a indagar sobre o espaço da sala de aula: como trabalhar o afeto na relação professor aluno? A sala de aula permite que possamos

\footnotetext{
${ }^{2}$ Tais projetos serão detalhados mais adiante no momento em que discorrerei sobre minha prática de maneira mais incisiva.
} 


\section{DIMENSÕES RELACIONAIS NA ESCOLA \\ Grupo de Pesquisa em Ensino Superior}

estabelecer relações de afetividade? Mas de que sala e de que aula estamos falando? Como vincular afinidade e cognição? Como humanizar as relações?

Analisando que este espaço ultrapassava o conceito historicamente socializado de transmissão única do saber, que aula não poderia ser definida de forma meramente conteudista, e que outras coisas importantes existiam neste espaço chamado sala de aula, como as relações afetivas socializadas e dinamizadas. Comecei a questionar: porque não levar os projetos para a sala de aula? Ou a sala de aula para os projetos? Como participante destes espaços comecei então a refletir a sala de aula como o espaço da aprendizagem do humano.

Neste momento de minha pesquisa comecei a identificar realmente qual era o meu foco de estudo, como parte integrante da sala de aula e dos projetos, descobri a necessidade de transitar por estes dois espaços de interações pessoais e mais do que isso, transpassa-los à medida de se tornarem um único espaço, o de aprendizagem do humano.

A partie de então, passei a acreditar na sala de aula como o espaço dos encontros, dos gestos, das palavras, do movimento, de aprendizagem do sensível, da relação de gente com gente, humanizado, socializado, dinamizado, capaz de transportar relações que extrapolem os livros, que se transportem para além da sala de aula, para a vida.

Durante este ano letivo, através das discussões semanais, integrando todos os professores e funcionários desta unidade escolar, juntamente com o apoio da Universidade, e mais especificamente as discussões teóricas realizadas nos grupos de estudo, com o apoio da Fapesp, pude relacionar minha prática educativa com as teorias discutidas, a caminho de estabelecer relações entre teoria e prática.

\section{MEUS E NOSSOS ESPAÇOS TRANSPONÍVEIS, NOSSA PRÁTICA.}

Dediquei este momento de nossa conversa para explicar no que consistem estes dois espaços que chamo de transponíveis em minha pesquisa, o projeto Movimentarte e a Atividade Curricular Especial. Separei este momento para isso, pois posteriormente estarei descrevendo e analisando a minha prática docente a partir da vivência nestes dois espaços, o projeto e a sala de aula que se transformarão em sala projeto e projeto aula, na medida que, sincreticamente, transportarei e transitarei por eles para discutirmos as relações de afeto e aprendizagem do humano.

\section{PROJETO MOVIMENTARTE}

Projeto de dança construído a partir de uma parceria de duas professoras desta unidade escolar, eu, Gisele Gomes, formada em história e bailarina e Maristela Marçal, formada em educação física e 


\section{DIMENSÕES RELACIONAIS NA ESCOLA Grupo de Pesquisa em Ensino Superior}

pedagogia. Este projeto surgiu a partir de um sonho de tornar possível o contato com a dança e com a arte, levando os alunos a vivenciarem outras manifestações corporais. O nosso objetivo consistiu em possibilitar a vivência da dança vinculada à arte da recriação do movimento e da expressão corporal, de modo prazeroso e lúdico, proporcionando a auto descoberta, a integração com o outro e com o seu meio físico e social.

O projeto tinha aproximadamente oitenta alunos, divididos em quatro grupos, sétimas e oitavas séries, sexta série, primeira e segunda série, terceiras quartas e quintas séries, com aulas em horários diferentes, as aulas aconteciam no refeitório, uma vez por semana, com duração de uma hora, no período de março a dezembro de 2004.

O nome do projeto Movimentarte surgiu de uma eleição com os alunos, que escolheram entre dois nomes: Movimentarte ou Expressarte, este projeto atendia todos os alunos da escola, sendo de caráter facultativo.

O encerramento deste trabalho ocorreu através de um festival de dança chamado Encontros, que contou um pouco da história da música e da dança a partir do resgate histórico da memória musical utilizando outras linguagens artísticas como: teatro, poesia e expressão corporal.

\section{ATIVIDADE CURRICULAR ESPECIAL E MÓDULO}

Disciplina pioneira na rede municipal, criada a partir do projeto “Escola Singular Ações plurais”, cujo objetivo consistia em introduzir conceitos de Filosofia, Ética e Cidadania (FEC) para sextas sétimas e oitavas séries do ensino fundamental.

Como caracteriza-se por um currículo a ser construído fundamentou-se basicamente nos eixos temáticos propostos pelo plano pedagógico desta unidade escolar: Eu e o outro, eu e o grupo, eu e o mundo.

Atendia no período da tarde duas sextas, duas sétimas e uma oitava série, com aproximadamente trinta alunos cada uma, e no período da manhã atendia uma oitava série com trinta e cinco alunos, que tinham aula em um esquema semi modular.

Em função deste projeto uma das mudanças nesta unidade escolar foi repensar o próprio tempo escolar, desta forma, o ano letivo era dividido trimestralmente e não mais bimestralmente, a maioria das aulas eram triplas ou duplas e a oitava série A e a quinta série A do período da manhã vivenciavam o semi modular.

O semi módulo permitia que dois professores de disciplinas diferentes dividissem determinado tempo do trimestre com determinada sala, os alunos ficavam vinte e cinco dias, por exemplo tendo aula (C) ETD - Educação Temática Digital, Campinas SP, v.7 , n. esp., p.33-45, jun. 2006 - ISSN: 1676-2592 


\section{DIMENSÕES RELACIONAIS NA ESCOLA \\ Grupo de Pesquisa em Ensino Superior}

de português e ciências, depois mudavam se as disciplinas, no caso de FEC ocorria o módulo, ficávamos seis dias tendo cinco aulas diárias desta disciplina.

Um dos objetivos era permanecer mais tempo com seu aluno, e isto permitia conhecê-los melhor e planejar as aulas de maneira mais motivadora.

\section{RELAÇÃO PRÁTICA E TEORIA - PROJETO MOVIMENTARTE E ATIVIDADE CURRICULAR ESPECIAL: TRANSFORMAR O ESPAÇO EM PROJETO E O PROJETO EM ESPAÇO}

A proximidade do trabalho com arte, com as diferentes linguagens artísticas, surgiu a partir das aulas de dança e da disciplina Atividade Curricular Especial (Filosofia, Ética e Cidadania).

Mesmo caracterizados como projetos distintos, e realizados em espaços físicos diferentes, no decorrer do trabalho se unificaram, e estes momentos de junção contribuíram muito na construção da relação professor-aluno e no início da discussão do que seria o espaço de aula.

Devido ao pouco tempo de discussão dos temas teóricos que embasam este trabalho, e o fato das discussões teóricas surgirem posteriormente à elaboração dos projetos, não pude responder todas as questões levantadas no início do trabalho.

Apesar dessa dificuldade, centrei minha discussão na importância da afetividade na relação professor-aluno transportadas para a sala de aula e para os projetos.

O projeto de dança surgiu do objetivo comum de trabalhar a manifestação corporal na arte de dançar. Quando iniciamos as aulas de dança, sentíamos que nossas crianças traziam na expressão através do corpo, movimentos prontos e padronizados, a aula de dança era, para elas, o espaço do axé e do "street dance”. Neste momento, surgia o nosso primeiro desafio; oferecer uma experiência que quebrasse, ou melhor, acrescentasse a esta vivência corporal algo que viesse além destes padrões construídos. Seria necessário trabalhar experiências corporais referentes a diversos ritmos, tempoespaços, linguagens do corpo, dos sentidos, da expressividade e da ludicidade do dançar.

O projeto movimentarte, a partir de dois olhares distintos tornou-se a junção de duas formações específicas, o movimento e a expressão espontâneos e populares, com a técnica clássica, a musicalidade rítmica e a expressão corporal.

Esta abertura ao novo vivenciada por nós, professoras do projeto, nos permitiu uma diferente aprendizagem com a dança, quando vivenciamos movimentos, músicas, propostas dos alunos, que em alguns casos não havíamos nos aprimorado ainda, e este contato com a arte de dançar intensificou 


\section{DIMENSÕES RELACIONAIS NA ESCOLA Grupo de Pesquisa em Ensino Superior}

nossos laços de afetividade entre nós professoras, a partir da troca de experiências, do planejamento das atividades, do processo ensino-aprendizado, das inúmeras dificuldades e das grandes surpresas.

Começamos nosso trabalho sentindo que mais importante que o ato de dançar estava a busca do sensível, ou seja, trazer para este ato aquilo que se sente, expondo o que se é. Para que isso pudesse acontecer, planejamos nossos encontros mesclando vivências e práticas corporais do individual em construção para o coletivo, e a partir daí, pequenas seqüências coreográficas, utilizando diferentes estilos e ritmos musicais.

O primeiro momento de nosso encontro tinha como finalidade brincar com o corpo, com o espaço e com o ritmo, momento em que nos descobríamos e descobríamos o outro através do movimento. O tocar, o brincar, o contato com o chão, com a música, com os diferentes ritmos permitia a improvisação do movimento e a descoberta do próprio corpo.

O segundo momento caracterizava-se pela construção de seqüências coreográficas, com estilos musicais diferentes, a partir das criações individuais e coletivas realizadas no primeiro momento enfatizando técnica e postura corporal.

Enfatizo o momento dos nossos encontros, pois acredito que desta vivência com os alunos, em que o professor tornava-se parte integrante do grupo, expondo seu corpo, sua dança, interagindo com seus alunos e possibilitando a construção de algo coletivo, foi essencial para intensificar as relações interpessoais e afetivas no grupo.

Criamos um espaço na escola em que tornou possível o movimentar, o pular, o correr, o gritar, o abraçar, o tocar e o sentir. Espaço este muitas vezes inexistente na sala de aula, onde o movimento, muitas vezes, é sinônimo de desatenção e quase sempre interpretado como indisciplina. Perde-se de vista e ignora-se um importante atributo do movimento: sua capacidade de representar as emoções.

A aula de dança na escola, os conflitos nela existentes, (muitas vezes por medo da exposição do corpo, do conhecer o novo, de arriscar novos espaços e ritmos, o entrosamento entre os alunos, professores, a aceitação e o reconhecimento do processo de construção de si e do outro) se transformaram em um espaço rico de construção do saber. À medida que, coletivamente, construímos movimentos, vivenciamos o toque, a música respeitávamos o tempo e a possibilidade do outro. Este contato entre eu e os alunos, em muitos momentos, ultrapassou o espaço do refeitório, onde aconteciam as aulas de dança, chegando até o espaço chamado sala de aula. Isto no momento em que transitava do espaço do projeto de dança para as aulas de FEC.

Em minha prática como professora ficava muito evidente a importância da relação professor aluno no processo de ensino-aprendizagem. Esta relação parecia tornar-se mais evidente ainda nas 


\section{DIMENSÕES RELACIONAIS NA ESCOLA Grupo de Pesquisa em Ensino Superior}

aulas de dança, quando me transformava muitas vezes em aluna, em momentos de construção coletiva, ou de construção de coreografias. Era nítido que a diferença de formação se misturava com os movimentos e com o entusiasmo dos alunos; éramos um grupo.

Esta relação de afeto, respeito e cumplicidade chegava inevitavelmente à sala de aula, mais especificamente nas aulas de atividade especial.

A partir deste momento, que me vi transitando por estes dois espaços, (aula e projeto) alguns questionamentos em relação à minha prática tornaram-se ainda mais importantes e instigantes. O trabalho com as linguagens artísticas propiciava uma maior aproximação na relação professor-aluno? Seria possível transportá-lo para o espaço da sala de aula?

Neste espaço chamado sala de aula, (dedico-me agora a discorrer um pouco sobre as aulas de FEC) encontravam-se comigo, semanalmente, alunos que participavam e que não participavam das aulas de dança. Ficava evidente que existia um maior entrosamento entre os alunos do projeto e eu em relação a aqueles que não participavam. Por que isso acontecia? O que é que faltava nesse processo? Como era uma disciplina nova, os alunos não sabiam como ela iria se desenvolver. (e, sinceramente, nem eu!) Um dos meus objetivos principais, ao elaborar os temas das aulas de FEC, era desenvolver junto aos alunos conceitos relacionados ao próprio dia-a-dia, enfocando questões relacionadas ao autoconhecimento, história de vida, projetos de vida, valores construídos, a vivência com o outro, a cidadania dentro da escola, levando em conta, sempre, que este espaço deveria ser especial de alguma forma. E por que não um espaço para expor o que somos e o que sentimos?

Meu primeiro desafio nesse processo centrou-se na elaboração do próprio planejamento; que temas selecionar, que textos escolher, como interagir com a vivência destes alunos trabalhando o conceito de filosofia.

No segundo momento, dediquei-me a pensar nas estratégias de aula que pudessem me aproximar da realidade dos alunos para que estes entendessem a proposta da própria disciplina.

A partir destes desafios, comecei, então, a elaborar as aulas de FEC como se fossem pequenos projetos: oficinas em que discutíamos determinados assuntos diversificando: aula expositiva, trabalho em grupo, filmes, estratégias de aula, utilizando diferentes linguagens artísticas.

Comecei a trazer o projeto movimentarte para dentro da sala de aula, modificando o espaço das carteiras, da lousa e do giz, momento que enfatizo que deixei simplesmente de transitar pelos espaços e me desafiei a transportá-los, trazendo para a sala de aula a arte e o afeto.

Um encontro de aula que julgo interessante resgatar neste momento aconteceu na oitava série “A” durante as aulas do módulo. Nossa discussão centrou-se no tema: eu e o outro, resgatamos a 


\section{DIMENSÕES RELACIONAIS NA ESCOLA Grupo de Pesquisa em Ensino Superior}

importância do outro na construção de nós mesmos, ou seja, eu existo a partir do outro. No primeiro momento fizemos dois círculos em sala, o círculo de dentro andava e o de fora ficava parado. A estratégia consistia em fazer as pessoas conversarem e se conhecerem, depois que cada um do grupo de dentro tivesse conversado com o de fora, invertíamos os círculos, o objetivo desta estratégia consistia em permitir que os alunos conversassem e trocassem experiências, tentando descobrir o que poderiam aprender com o outro.

Nos depoimentos dos alunos, muitas sensações foram expressas, como: “Nunca havia conversado com aquela pessoa.” “Não sabia o que falar.”, “Foi super legal, nem vi a aula passar.”, “É a primeira vez que um professor pedia pra gente andar e falar.”, "A aula parecia uma bagunça."

Resgatamos a discussão de como o outro é importante na nossa formação e de como aprendemos com ele. Neste momento, usamos o espaço de aula para nos movimentar, falar, expor sentimentos e brincar, e foi brincando de roda que formamos um grande círculo, registrando corporalmente, através da união das pessoas, a importância do grupo em nossa formação.

No final do módulo escutamos a poesia “Metade” (Oswaldo Montenegro), e partindo da idéia que somos um pouco de cada um que convive conosco, fizemos máscaras de tala gessada no rosto do colega. Cada um cortava a tala em pequenos pedaços, molhava estes pedaços e colocava no rosto do colega, depois de seca, no formato de seu próprio rosto, registravam com guache o que sentiam e o que eram. Os depoimentos dos alunos registrando os sentimentos ficaram assim: "Isso foi muito legal.”, “Melhor aula que já tive.”, “Foi horrível esperar o gesso secar.”, “Não dava pra falar.”, “Fiquei dependendo do meu colega”, “Sem o outro não dava pra fazer a atividade.”, "Pintei várias cores, são todos que fazem parte do que sou.”, “A aula de FEC faz a gente pensar na gente.”, “A professora não podia falar, que legal.”, (a professora também participou da elaboração da máscara, e estava com o gesso no rosto.) “Parecia uma aula de artes.”, “A poesia fala da gente, que é adolescente.”, “Pintei como se fosse índio, é um registro de uma parte do passado que carrego comigo”.

Foram estas frases expressas pelos alunos que me fizeram perceber que a sala de aula tornou-se o espaço eleito das relações de afetividade, não por acaso, mas pelo nosso empenho e abertura de se propor ao novo. Este trabalho por nós realizado foi construído e planejado a partir de sonhos, ideais, do estudo dirigido apoiado pela escola e universidade, fazendo a diferença.

Quando permitimos ao aluno expressar o que sente, o que pensa sobre aquilo que vem sendo construído curricularmente pelo professor, abrimos um espaço de sermos avaliados, um espaço para analisarmos se o que vem sendo feito está satisfatório, e quando permitimos a estes alunos entenderem 


\section{DIMENSÕES RELACIONAIS NA ESCOLA Grupo de Pesquisa em Ensino Superior}

a proposta e se apropriarem verdadeiramente dela, acreditamos ainda mais que o trabalho docente coletivo vale a pena.

Estas estratégias diferentes foram realizadas em todas as séries e aos poucos pude perceber que estas aulas diversificadas melhoravam muito o meu relacionamento com os alunos, afinal construímos um espaço de falar, sentir, dançar, pintar, fazer poesia, dentro daquele outro espaço de giz e lousa.

A sala de aula tornou-se, não por acaso, o espaço eleito das relações de afetividade, da construção do saber através da arte, da coletividade e da aprendizagem do humano.

Volto a afirmar que a utilização das diferentes linguagens artísticas, por trabalhar a sensibilidade, o reconhecimento de si nas construções corporais, pinturas, poesias, desenhos, torna-se um instrumento importantíssimo na relação professor-aluno, adquirindo o caráter de instrumento motivador no processo ensino-aprendizagem. A sala de aula deve ser o espaço facilitador deste processo de vivência entre pessoas e construção do afeto.

Percebi, quando questionei sobre o que faltava no processo, o que diferenciava inicialmente meu vínculo com os alunos do projeto e com os demais em sala de aula (FEC), que o trabalho com a arte é um mediador da relação professor aluno, o que também constrói a relação de afetividade neste processo são as relações que extrapolam as posições específicas do ser professor ou ser aluno. Quando o professor em alguns momentos ‘esquece’ de seu título de professor, escuta o que seu aluno sente, brinca, engessa o rosto, canta, dança, sente o olhar, o gesto, e se apropria verdadeiramente do grupo, ele torna-se mais um integrante do processo de conhecimento e de aprendizagem. Neste momento as relações de afeto entre passam as relações de poder e a escola, assim como a sala de aula, adquirem um outro significado.

$\mathrm{O}$ ato de ensinar e o de aprender envolvem certa cumplicidade do professor a partir do planejamento das suas decisões de ensino assumidas; mas tal cumplicidade também se constrói nas interações, através do que é falado, do que é entendido, do que é transmitido e captado pelo olhar, pelo movimento do corpo, que acolhe, observa e busca a compreensão do ponto de vista do aluno. (LEITE E TASSONI, 2002, p. 107)

\section{REFERÊNCIAS}

ALMEIDA, A. A emoção em sala de aula. Papirus, 1999.

ARAÚJO, U. A construção de escolas democráticas. história sobre a complexidade, mudanças e resistências. Editora Moderna, 2002.

(C) ETD - Educação Temática Digital, Campinas SP, v.7 , n. esp., p.33-45, jun. 2006 - ISSN: 1676-2592 


\section{DIMENSÕES RELACIONAIS NA ESCOLA Grupo de Pesquisa em Ensino Superior}

LEITE, S. e TASSONI, E. “A afetividade em sala de aula: As condições de ensino e a mediação do professor”. In: AZZI, R. G. E SADALLA, A. M. F. (orgs). Formação docente: desafios e conversas. São Paulo: Casa do Psicólogo, 2002.

MORAES, R. Sala de aula, que espaço é esse?. São Paulo: Papirus, 1994.

GISELE FILIPPINI GOMES
Professora, licenciada em História e
Dançarina. Assumiu no ano de 2004, na
EMEF Padre Francisco Silva, as aulas da
disciplina Filosofia Ética e Cidadania,
ministrada para os alunos de $5^{a}$ à $8^{a}$ séries.

Artigo recebido em: 10/01/2006-05 Aceito para publicação em: 09/05/2006 